\title{
STUDY ON EFFICACY OF NALBUPHINE HYDROCHLORIDE AS PRE-EMPTIVE ANALGESIC - COMPARISON WITH DICLOFENAC SODIUM AFTER OPEN CHOLECYSTECTOMY
}

\author{
Md. Quamrul Islam, Hasina Begum², A.K.M. Akhtaruzzaman ${ }^{3}$, U.H. Shahera Khatun ${ }^{4}$
}

\begin{abstract}
Preemptive analgesia is an antinociceptive treatment that prevents establishment of altered central processing of afferent input from sites of injury. The aim of this study was to evaluate the effects of preemptively used nalbuphine and diclofenac on postoperative pain and opioid consumption. Seventy five patients scheduled for open cholecystectomy were investigated by randomized study. Patients were divided into three groups. In group I, patients received Inj. Nalbuphine Hydrochloride $(0.3 \mathrm{mg} / \mathrm{kg}$ bw IV) before induction. In group II, patients received Inj. Diclofenac Sodium (1 $\mathrm{mg} / \mathrm{kg}$ bw IV) before induction and in group III patients received placebo before induction. General Anesthesia was given in all groups with Inj. Thiopental sodium $5 \mathrm{mg} / \mathrm{kg}$ and Inj. Succninylcholine $1.5 \mathrm{mg} / \mathrm{kg}$ to facilitate endotracheal intubation. Anesthesia was maintained with halothane $0.5 \%$ and nitrous oxide $66 \%$ in oxygen. Muscle relaxation was maintained by Inj.Vecuronium $0.1 \mathrm{mg} / \mathrm{kg}$. Intraoperative proper hydration was maintained by lactate ringer's solution.In post operative period patients in all three groups received Inj. Pethidine 10mg IV till the patients got relieved from pain. The minimum interval of giving pethidine was 10 minutes. Through our study we have found that, pethidine consumption in 24 hours in group-I (Nalbuphine

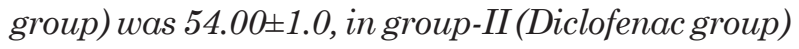
was $74.00 \pm 1.0$ and in group-III (Placebo group) was 112.0 \pm 2.0 and p-value $<0.001$, which is highly significant (measured in $\mathrm{mg}$ ). Time of first pethidine demand in group-I was $45.83 \pm 10.93$, in group-II was $34.20 \pm 5.44$ and in group-III was $16.21 \pm 3.62$ and
\end{abstract}

p-value $<0.001$ which is also highly significant (measured in minute). Overall patients satisfaction was high in nalbuphine group. Under the condition of present study, we can conclude that preemptively used nalbuphine hydrochloride decreases post operative pain and opioid demand.

\section{INTRODUCTION}

Pain is not just a sensory modality but an experience. The International Association for the Study of Pain defines pain as an unpleasant sensory and emotional experience associated with actual or potential tissue damage, or described in terms of such damage ${ }^{1}$.

The word anaesthesia means without feeling, without pain. Our goal is the prevention of pain. While this goal is almost universally achieved in the operating room, the same guarantee cannot be made for postoperative pain. We already have knowledge and the medications required to prevent postoperative pain. Complete patient control is limited more by a lack of commitment to this issue rather than a lack of potent analgesic agents ${ }^{2}$.

Preemptive analgesia is prior administration of analgesic in a patient undergoing surgery. It is a new concept of analgesia. This type of management pharmacologically induces an effective analgesic state prior to surgical trauma. This may involve infiltration of wound with local anaesthetic, central neural blockade, or administration of effective doses of opioids, NSAIDS or ketamine ${ }^{3}$.

Nalbuphine Hydrochloride is a synthetic opioid analgesic. It effectively relieves pain ${ }^{4}$. binds with

1. Anaesthetist, NICVD, Dhaka

2. Assistant Professor, Department of Anaesthesiology, Dhaka Dental College, Dhaka

3. Associate Professor, Dept. of Anaesthesia, Analgesia and Intensive Care Medicine, BSMMU,

4. Professor \& Head, of the Department of Anaesthesiology and Intensive Care Unit, DMCH. 
$\mathrm{m}, \mathrm{k}$ and $\mathrm{d}$ receptors.Its analgesic potency is equivalent to morphine on a milligram basis and 10 times more potent than pentazocine but has fewer side effects and less abuse to potential than morphine. It is effective and safe analgesic for different pain episodes ${ }^{5}$. Safety and tolerability of nalbuphine is superior to morphine and pethidine ${ }^{6}$.It is a rational alternative to morphine in intra and postoperative pain ${ }^{7}$.

Diclofenac, as the sodium salt is benzeneacetic acid derivative. As with other NSAIDs, its mode of action is not known. Its ability to inhibit prostaglandin synthesis, however may be involved in its antiinflammatory activity, as well as contribute to its efficacy in relieving pain related to inflammation and primary dysmenorrhoea ${ }^{8}$. Diclofen increases platelet aggregation time, but does not affect bleeding time, plasma thrombin clotting time, plasma fibrinogen or factors V and VII to XII.

So far literature reviewed there is no standard study yet that compare the efficacy of Nalbuphine Hydrochloride with Diclofenac sodium as preemptive analgesic in open cholecystectomy patient.So it has decided to compare the effect of Nalbuphine Hydrochloride Diclofenac sodium as preemptive analgesic in open cholecystectomy patients.

For this the present study was designed to assess the efficacy of the study drugs through post operative opioid consumption and thereby to make an effort for better post operative pain management and patient's satisfaction.

Our aim was to assess the efficacy of Nalbuphine Hydrochloride over Diclofenac sodium as preemptive analgesic in postoperative pain management after open cholecystectomy.

\section{MATERIALS AND METHODS:}

It was a randomaized prospective case control clinical study. Seventy five patients were divided equally into three groups each of which consisted of twenty five patients. The study was performed in the Department of Anaesthesiology and Intensive Care Unit, Dhaka Medical College Hospital in the period from January 2005 to December 2006.

\section{GROUPING OF THE SUBJECTS:}

75 adult patients underwent open cholecystectomy were selected.The patients were randomly divided into three groups each receiving different drugs.

Group-I: $\quad$ Consisted of 25 patients receiving Nalbuphine Hydrochloride $(0.3 \mathrm{mg} /$ kg b.w. I/V)

Group-II: $\quad$ Consisted of 25 patients receiving Diclofenac sodium (1 mg/kg b.w. I/ V)

Group-III: Consisted of 25 patients receiving placebo.

\section{RESULTS}

Observation of the present study was analysed in the light of comparison among each subject groups. Each group having $n=25$. All results were expressed as mean $\pm \mathrm{SEM}$ or in frequencies as applicable. The groups became statistically matched for age $(\mathrm{P}=0.844)$, weight $(\mathrm{P}=0.906)$, duration of operation $(\mathrm{P}=0.923)$, base line pulse rate $(\mathrm{P}=0.938)$

Table-I

Demographic data of the study subjects $(n=75)$

\begin{tabular}{lcccc}
\hline \multicolumn{1}{c}{ Variables } & Group-I $(\mathrm{n}=25)$ & Group-II $(\mathrm{n}=25)$ & Group-II $(\mathrm{n}=25)$ & P value \\
\hline Age (years) & $38.0 \pm 2.01$ & $37.2 \pm 2.25$ & $38.8 \pm 1.50$ & $0.844^{\mathrm{ns}}$ \\
Weight (kg) & $54.2 \pm 1.61$ & $53.3 \pm 1.67$ & $55.4 \pm 1.22$ & $0.906^{\mathrm{ns}}$ \\
Duration of surgery (min) & $73.0 \pm 1.38$ & $72.0 \pm 2.29$ & $72.0 \pm 2.29$ & $0.923^{\mathrm{ns}}$ \\
Baseline pulse rate (beats/min) & $96.4 \pm 0.86$ & $97.2 \pm 4.16$ & $97.6 \pm 0.87$ & $0.938^{\mathrm{ns}}$ \\
\hline
\end{tabular}

Values were expressed as mean \pm SEM. Beween groups analysis were done by one way ANOVA. There was no significant differences among the groups.

Group-I=Subjects got Nalbuphine Hydrochloride.

Group-II = Subjects got Diclofenac sodium.

Group-III = Subjects got placebo.

$\mathrm{n}=$ Number of subjects. $\mathrm{ns}=$ Not significant. 
Assessment of pain with Visual Analogue Scale (VAS):Mean values of visual analogue scale(VAS) in group-I varies from $16.00 \pm 1.73$ to $52.40 \pm 1.66$ being highest 1 hour after arrival in post op Mean values of blood pressure in group-II varies from $87.0 \pm 0.82$ to $104.8 \pm 4.73$ being highest six hours after arrival in post operative room. Mean values of blood pressure in group-III varies from $85.6 \pm 0.83$ to 107.0 \pm 8.38 being highest six hours after arrival in post operative room.(measured in $\mathrm{mmHg}$ ).
Overall patient satisfaction in 24 hours in post operative period by verval rating scale (VRS).After 24 hours overall patient satisfaction was assessed. In group-I, 8 patients rated "moderatetly effective", 14 "effective" and 3 "excellent". In group II, 3 patients rated "not effective at all", 8 "moderately effective", and 14"effective" In group-III, 10 patients rated ".not effective at all", 11 "moderately effective" and 4 "effective.

Table-II

Changes in VAS in post operative period $(n=75)$

\begin{tabular}{lccccc}
\hline & $\begin{array}{c}\text { 1hr after } \\
\text { end of opn. }\end{array}$ & $\begin{array}{c}6 \text { hr after } \\
\text { end of opn. }\end{array}$ & $\begin{array}{c}12 \mathrm{hr} \text { after } \\
\text { end of opn. }\end{array}$ & $\begin{array}{c}\text { 18hr after } \\
\text { end of opn. }\end{array}$ & $\begin{array}{c}\text { 24hr after } \\
\text { end of opn. }\end{array}$ \\
\hline Gr-I (n=25) & $52.40 \pm 1.66$ & $35.60 \pm 1.01$ & $28.00 \pm 0.82$ & $18.40 \pm 2.29$ & $16.00 \pm 1.73$ \\
Gr-II (n=25) & $55.60 \pm 3.06$ & $60.00 \pm 1.91$ & $46.00 \pm 1.63$ & $27.00 \pm 3.98$ & $22.80 \pm 2.86$ \\
Gr-III(n=25) & $61.60 \pm 2.43$ & $61.20 \pm 2.60$ & $52.00 \pm 2.00$ & $29.20 \pm 3.26$ & $28.40 \pm 5.12$ \\
F-value & 3.633 & 54.600 & 63.818 & 3.083 & 3.093 \\
P-value & $0.031^{*}$ & $<0.00^{* * *}$ & $<0.001^{* * *}$ & $0.052^{\text {ns }}$ & $0.051^{\text {ns }}$ \\
\hline
\end{tabular}

Values were expressed as mean \pm SEM. Between groups analysis was done by one way ANOVA. Values were significant between groups.

Group-I=Subjects got Nalbuphine Hydrochloride. Group-II = Subjects got Diclofenac sodium. Group-III = Subjects got placebo.

$*$ = Significant at $\mathrm{p}<0.05$ level, $* * *=$ Significant at $\mathrm{p}<.001$ level, $\quad$ ns $=$ Not significant

Overall patient satisfaction by Verval Rating Scale (VRS) (Table-III):

Table-III

Changes in VRS in post operative period $(n=75)$

\begin{tabular}{lccccc}
\hline Variables & $\begin{array}{c}\text { Group-I } \\
(\mathrm{n}=25)\end{array}$ & $\begin{array}{c}\text { Group-II } \\
(\mathrm{n}=25)\end{array}$ & $\begin{array}{c}\text { Group-III } \\
(\mathrm{n}=25)\end{array}$ & $\chi^{2}$ & P value \\
\hline Not effective at all & $0(.0) \%$ & $3(12.0) \%$ & $10(40.0 \%)$ & & \\
Moderately effective & $8(32.0 \%)$ & $8(32.0 \%)$ & $11(44.0 \%)$ & & \\
Effective & $14(56.0 \%)$ & $14(56.0 \%)$ & $4(16.0 \%)$ & 22.19 & $<0.001^{* * *}$ \\
Excellent & $3(12.0 \%)$ & $0(0 \%)$ & $0(.0 \%)$ & & \\
\hline
\end{tabular}

Values are expressed in frequency within parenthesis percentage over column total. Between groups analysis were done by $\chi^{2}$ test. Values were significant between groups.

Group-I=Subjects got Nalbuphine hydrochloride, Group-II = Subjects got Diclofenac

Group-III $=$ Subjects got placebo.

$* * *=$ Significant at $\mathrm{p}<.001$ level

Sedation score:

Mean values of sedation score in group-I varies from $1.20 \pm 0.20$ to $3.20 \pm 0.25$ Mean values of sedation score in groupII varies from $1.20 \pm 0.08$ to $3.52 \pm 0.32$. Mean values of sedation score in group-III varies from $1.60 \pm 0.10$ to $3.88 \pm 0.35$. 
Table-IV

Changes in Sedation score in post operative period (Ramsay scale) ( $n=75)$

\begin{tabular}{lccccc}
\hline & $\begin{array}{c}\text { 1hr after } \\
\text { end of op. }\end{array}$ & $\begin{array}{c}\text { 6hr after } \\
\text { end of op. }\end{array}$ & $\begin{array}{c}\text { 12hr after } \\
\text { end of op. }\end{array}$ & $\begin{array}{c}\text { 18hr after } \\
\text { end of op. }\end{array}$ & $\begin{array}{c}\text { 24hr after } \\
\text { end of op. }\end{array}$ \\
\hline Gr-I (n=25) & $3.20 \pm 0.25$ & $2.04 \pm 0.25$ & $1.20 \pm 0.20$ & $1.20 \pm 0.20$ & $1.20 \pm 0.20$ \\
Gr-II(n=25) & $3.52 \pm 0.32$ & $2.56 \pm 0.27$ & $2.36 \pm 0.48$ & $1.80 \pm 0.37$ & $1.20 \pm 0.08$ \\
Gr-III(n=25) & $3.88 \pm 0.35$ & $3.04 \pm 0.34$ & $2.16 \pm 0.42$ & $2.64 \pm 0.47$ & $1.60 \pm 0.10$ \\
F-value & 1.219 & 2.961 & 2.631 & 2.981 & 2.824 \\
P-value & $0.302^{\text {ns }}$ & $0.058^{\text {ns }}$ & $0.079^{\text {ns }}$ & $0.056^{\text {ns }}$ & $0.066^{\text {ns }}$ \\
\hline
\end{tabular}

Values were expressed as mean \pm SEM. Between groups analysis was done by one way ANOVA. Values were not significant between groups.

Group-I=Subjects got Nalbuphine Hydrochloride. Group-II = Subjects got Diclofenac sodium. Group-III=Subjects got placebo . ns $=$ Not significant

Time of first pethidine demand:

Mean values of time of first pethidine demand in post operative period in group-I was $45.83 \pm 10.93$, in group-II was $34.20 \pm 5.44$, in group-III was $6.21 \pm 3.62$ (measured in min).

Table-V

Changes in pethidine taking time in post operative period $(n=75)$

\begin{tabular}{lc}
\hline & $\begin{array}{c}\text { Time of first pethidine } \\
\text { demand }\end{array}$ \\
\hline Group-I $(\mathrm{n}=25)$ & $45.83 \pm 10.93$ \\
Group-II(n=25) & $34.20 \pm 5.44$ \\
Group-III(n=25) & $16.21 \pm 3.62$ \\
F-value & 64.32 \\
P-value & $<0.001^{* * *}$ \\
\hline
\end{tabular}

Values were expressed as mean \pm SEM. Between groups analysis were done by one way ANOVA.Values were significant between groups

Group-I=Subjects got Nalbuphine Hydrochloride, Group$\mathrm{II}=$ Subjects got Diclofenac sodium, Group $-\mathrm{III}=$ Subjects got placebo. ${ }^{* * *}=$ Significant at $\mathrm{p}<.001$

Total pethidine consumption (Table - IV)

Mean values of total pethidine consumption in post operative period in group-I was $54.00 \pm 1.0$, in group-II was $74.00 \pm 1.0$, in group-III was $112.00 \pm 2.0$ (measured in $\mathrm{mg}$ ).

\section{DISCUSSION}

Preemptive analgesia is an antinociceptive treatment that prevents establishment of altered central processing of afferent input from sites of injury ${ }^{9}$. The most important conditions for establishment of effective pre-emptive analgesia are the establishment of an effective level of
Table-VI

Changes in total pethidine consumption in post operative period

\begin{tabular}{lc}
\hline & Pethidine Consumption \\
\hline Group-I & $54.00 \pm 1.0$ \\
Group-II & $74.00 \pm 1.0$ \\
Group-III & $112.00 \pm 2.0$ \\
F-value & 434.00 \\
P-value & $<0.001^{* * *}$ \\
\hline
\end{tabular}

Values were expressed as mean \pm SEM. Between groups analysis were done by one way ANOVA .Values were significant between groups

Group-I=Subjects got Nalbuphine Hydrochloride.

Group-II = Subjects got Diclofenac sodium .

Group-III $=$ Subjects got placebo.

$* * *=$ Significant at $\mathrm{p}<.001$

antinociception before injury and the continuation of this effective analgesic level well into the post injury period to prevent central sensitization during the inflammatory phase. The concept of preemptive analgesia was formulated by Crile at the beginning of previous century on the basis of clinical observation ${ }^{10}$. Later revival of this idea was 
associated with a series of animal studies started by Woolf 1983; Clifford $1993^{11}$.

The concept that analgesia given before the painful stimulus has effects that long out last the presence of the analgesic in the body created the basis for the preemptive treatment of pain ${ }^{12}$.

The aim of such treatment to prevent the spinal cord from reaching a hyperexcitable state in which it responds excessively to afferent inputs. The concept of preemptive analgesia originates primarily from basic science studies ${ }^{13,14}$. There is both scientific and clinical interest in this phenomenon. The clinical interest is in the potential for improving postoperative pain management ${ }^{15}$.

Opioid agonist-antagonist analgesics have been used clinically for the management of pain $16,17,18,19$. Nalbuphine has antagonist activity at $m$ receptors and agonist activity at $\mathrm{k}$ receptors ${ }^{17}$. As a result of these pharmacological characteristics, the incidence of addiction and respiratory depression with their use is lower than with the pure opioid agonists. Equivalent doses of nalbuphine and butorphanol to morphine $10 \mathrm{mg}$ are $10 \mathrm{mg}$ and 2 $\mathrm{mg}$, respectively. Among these drugs, nalbuphine is widely used clinically $17,18,19$.

Pharmacologically, pure opioid agonists are not considered to be good candidates for the preparation of long acting formulations because of safety consideration. Pure opioid agonists such as morphine and fentanyl can cause severe respiratory depression in high doses, without a ceiling effect. It is a problem if a large amount of drug is accidentally released from the formulation into the blood stream. In contrast, mixed opioid agonist-antagonists are relatively safer and have a ceiling effect on respiratory depression $16,17,18$.

In a study, a clinical comparison of the intraoperative, recovery and post operative effect of buprinorphine, diclofenac, fentanyl, morphine, nalbuphine, pethidine and placebo given intravenously with induction of anaesthesia showed, diclofenac exhibit no sedative, analgesic, analgesic sparing, emetic or anytipyretic effects ${ }^{19,20}$. Nalbuphine and pethidine produced sedation with analgesia during recovery, a prolonged time to remedication and a mild emetic effect. The study concluded that nalbuphine and pethidine, given individually as a single i.v. bolus during induction of anaesthesia, are the most efficacious analgesics for routine in-patient ENT surgery .

In another study, comparison, by intravenous route, following cholesystectomy showed overall pain relief (visiual analogue score) was recorded by the patients as 50(SEM4) for nalbuphine, 44(SEM 4) for morphine and 53(SEM5) for pethidine. These scores were not significantly different. The mean demand for each drug over the 24-hour period was 70(SEM 12) $\mathrm{mg}$ for nalbuphine, 46(SEM 6) $\mathrm{mg}$ for morphine and 614(SEM 49) $\mathrm{mg}$ for pethidine. Nalbuphine is a useful postoperative analgesic, as effective as pethidine. Nalbuphine $15 \mathrm{mg}$ is apparently equipotent with morphine $10 \mathrm{mg}$ or pethidine 120 $\mathrm{mg}$ by this mode of administration ${ }^{21}$.

To avoid the well known side effects of opioids like respiratory depression, dependency we tried to curtail the consumption of opioid in post operative period through our study. Our results indicate that the preemptive administration of nalbuphine markedly decreases the opioid consumption in post operative period. Through our study we have found that pethidine consumption in 24 hours in group-I (Nalbuphine group) was $54.00 \pm 1.0$ in group-II (Diclofenac group) was $74.00 \pm 1.0$ and in group-III (Placebo group) was $112.0 \pm 2.0$ and p-value 0.001 , which is highly significant (measured in $\mathrm{mg}$ ). Time of first pethidine demand in group-I was $45.83 \pm 10.93$, in group-II was $34.20 \pm 5.44$ and in group-III was $16.21 \pm 3.62$ and p-value 0.000 which is also highly significant (measured in minute). Overall patient satisfaction was high in nalbuphine group.

Abram and Yaksh using the rat formalin model of pain, demonstrated recently that the processes leading to pain induced spinal sensitization are not substantially suppressed by isoflurane. This suggests that halothane used in our study did not decrease difference between treatment groups.

Some authors ${ }^{15}$ regard preemptive analgesia as a preventive effect due to elimination of mechanical painful stimulation caused by surgery. We believe that the sustained hyper excitability is caused not only by direct surgical stimulation but also by the action of proteolytic and inflammatory drugs released into the injured tissue, which lasts longer than the surgery. This was the reason that nalbuphine and diclofenac was used in this study preemptively.

McQuay et al found that the median time to first analgesic request was significantly longer in the patients who received an opioid pre medication. This 
result was confirmed in a subsequent study ${ }^{22}$. Both studies were retrospective with a relatively short duration of surgeries. Our data demonstrating the decreased analgesic requirements in the nalbuphine group during the first $24 \mathrm{hrs}$ of the post operative period is convincing evidence for the preemptive effect of these drugs on post operative pain.

The most important result of our study is the profound preemptive effects of nalbuphine on reduction of post operative opioid consumption.

\section{CONCLUSION}

The effective relief of pain is of paramount importance to anyone treating patients undergoing surgery. This should be achieved for humanitarian reasons and to alleviate nociception-induced responses such as the endocrine metabolic response to surgery, autonomic reflexes with adverse effects on organ function, leading to muscle spasm, and other undesirable results ${ }^{23}$. The aim of postoperative pain relief is to provide subjective comfort in addition to inhibiting trauma induced nociceptive impulse to blunt autonomic and somatic responses to pain and subsequently to enhance restoration of function by allowing the patient to breathe, cough and move more easily ${ }^{24}$. On the basis of present randomized prospective comparative clinical study, it can be concluded that, preemptively used Nalbuphine Hydrochloride is better than Diclofenac Sodium in post operative pain management after open cholecystectomy and provides better comfort to the patient.

\section{REFERENCES}

1. Morgan G Edward, Mikhail S Marged, Clinical Anaesthesiology (Appleton and large) $3^{\text {rd }}$ Edition, p-311.

2. Moote CA. The prevention of postoperative pain. Can J Anaesth 1994; 41: 527-533.

3. Morgan G, Edward, Mikhail S Marged, Clinical Anaesthesioligy (Appleton and large) $3^{\text {rd }}$ edition, p-319.

4. www.npcentral.net

5. www.scinfo.org/nuabin

6. $\quad$ Emerg Med J 2002; 19:565-570.

7. J Pak Med Assoc Sep 2003; 53(9):391-6 .

8. www.rxlist.com/cgi/generic/diclofen.htm

9. Kelly DF, Ahmad M, Brull SJ. Preemptive analgesia I: physiological pathways and pharmacological modalities. Can J Anesth 2001; 48: 1000-1010.
10. Crile GW; The Kinetic theory of Shock and its presentation through anoci-association; Lancet 1913; 185: p 7-16.

11. Clifford J. Woolf, pre-emptive analgesia treating postopeartive pain. Anaesth, Analg 1993; 362-368.

12. Wall PD. The prevention of postoperative pain. Pain 1988; 33: 289-90.

13. Woolf CJ, Wall PD, Morphine sensitive and morphine insensitive actions of c-fibre input on the rat spinal cord. Neurosci Ltt 1986; 64:221225.

14. Cook AJ, Woolf CJ, Wall PD. Prolonged c-fibre mediated facilitation of the flexion reflex in the rat is not due to change in afferent terminal or motoneurone excitability. Neurosci Lett 1986; 70:91-96.

15. McQuay HJ. Pre-emptive analgesia. Br J Anaseth 1992; 69: 1-3.

16. Gutstein HB, Akil H. Opioid analgesics. In: Hardman JG, Limbird LE, Goodman Gilmman A,eds. Goodman and Gilman's the Pharmacological Basis of Therapeutics, $10^{\text {th }}$ Edn. New York: McGraw-Hill, 2001; 569-620.

17. Schmidt WK, Tam SW, Shotzberger GSD,Smith DH jr, Clark R, Vernier VG. Nalbuphine. Drug Alcohol Depend 1985; 14: 338-62.

18. Hoskin PJ, Hanks GW , Opioid agonistantagonist drugs in acute and chronic pain states. Drugs 1991; 41:326-44[ISI][Medline]

19. Van den BergAA, Honjol NM, Prabhu NV, Datta S, Rozario CJ, Savva D, Acta Anaesthesiol Scand,2005 Nov; 49(10): 1483-6.

20. Sanjoy Datta, The Obstetrics Anaesthesia handbook, $2^{\text {nd }}$ edition Mosby year Book (ed) 1995.

21. Bahar M, Rosen M, Vickers MD,1987 Apr;36(4):166-71.

22. Campbel WI. Analgesic side effects and minor surgery: which analgesic for minor and daycase surgery? Br J Anaesth 1990; 64:617-620.

23. Kehlet H. Postoperative pain. In: Wilmore DW, Brennan M, Harken A, et al., eds. Care of the surgical patient. New York: Scientific Americal Inc. 1988;12:1-2

24. Kehlet H. Dahl JB. The value of "Multimodal" or "Balanced Analgesia" in postoperative pain treatment. Anesth Analg 1993;77:1048-1056. 